\title{
Genetic diversity of Actinobacillus lignieresii isolates from different hosts
}

\author{
Branko Kokotovic ${ }^{1 *}$, Øystein Angen ${ }^{1}$, Magne Bisgaard ${ }^{2}$
}

\begin{abstract}
Genetic diversity detected by analysis of amplified fragment length polymorphisms (AFLPs) of 54 Actinobacilus lignieresii isolates from different hosts and geographic localities is described. On the basis of variances in AFLP profiles, the strains were grouped in two major clusters; one comprising strains isolated from horses and infected wounds of humans bitten by horses and another consisting of strains isolated from bovine and ovine hosts. The present data indicate a comparatively higher degree of genetic diversity among strains isolated from equine hosts and confirm the existence of a separate genomospecies for A. lignieresi-like isolates from horses. Among the isolates from bovine and ovine hosts some clonal lines appear to be genetically stable over time and could be detected at very distant geographic localities. Although all ovine strains investigated grouped in a single cluster, the existence of distinct genetic lineages that have evolved specificity for ovine hosts is not obvious and needs to be confirmed in other studies.
\end{abstract}

\section{Findings}

Actinobacillus lignieresii is a commensal of the oropharynx and rumen in cattle and sheep and has also been found in the oral cavity of healthy horses [1]. In bovine and ovine hosts the organism may cause pyogranulomatous inflammation, especially of the upper alimentary tract [2]. In horses it has been found in association with pyemic processes of soft tissues [3,4] and cases of stomatitis [1]. The virulence factors of $A$. lignieresii remain unknown. Different strains may vary in their ability to induce disease [5], but little progress has been made to identify reliable markers that will allow their epidemiological tracing. In addition, there is also limited information concerning genetic diversity in the natural population of the species.

Within the family Pasteurellaceae Pohl 1981 most taxa seem to be host specific [1]. However, very little is known about factors governing the ecological preferences that these taxa show for specific mucosal surfaces and hosts. Actinobacillus pleuropneumoniae and A. lignieresii are phenotypically very similar and their $16 \mathrm{~S}$ rDNA sequences differ only by two nucleotides [6].

\footnotetext{
* Correspondence: bkok@vet.dtu.dk

'Division of Veterinary Diagnostics and Research, National Veterinary Institute, Technical University of Denmark, Bülowsvej 27, DK-1790 Copenhagen V, Denmark

Full list of author information is available at the end of the article
}

Whole genome fingerprinting by amplified fragment length polymorphism (AFLP) analysis, however, provided a clear separation of these taxa affecting pigs and ruminants, respectively [7]. Distinct genetic lineages within the taxon 2 and 3 complex of Bisgaard also seem to have evolved host specificity for Columbidae, Anatidae and Psittacidae, respectively [8]. Bojesen et al. [9] suggested the divergence of at least three distinct Mannheimia granulomatis lineages that may have adapted to cervine, bovine and leporine hosts, respectively. In addition, Bojesen et al. [10] also suggested the existence of host adapted lineages within $M$. varigena. AFLP analysis has also separated bovine and ovine isolates of Bibersteinia trehalosi indicating the existence of separate ecotypes [11]. Evidence as to the existence of clonal lineages of Gallibacterium anatis adapted to different sites within the same animal has also been demonstrated by AFLP [12].

The aims of the present study were to investigate A. lignieresii isolates from different hosts in order to (1) determine discriminatory potential of AFLP for subspecies differentiation, (2) examine intraspecies genetic diversity and (3) investigate whether bovine and ovine isolates of $A$. lignieresii represent host specific subclones of this taxon.

The test population used in the study consisted of 54 A. lignieresii strains isolated from bovine $(\mathrm{n}=37)$, 
equine $(n=7)$ and ovine $(n=6)$ hosts, as well as one strain without host information and three strains isolated from infected wounds of humans bitten by horses (Table 1). The tested strains originated from different geographic localities including Australia, Belgium, Denmark, Norway, Sweden, United Kingdom, USA and Zimbabwe (Table 1). All strains were grown on Columbia agar (Oxoid A/S, Greve, Denmark) supplemented with $5 \%$ bovine blood and harvested after 48 -hours incubation at $37^{\circ} \mathrm{C}$ in atmospheric air.

Table 1 Actinobacillus lignieresii strains analysed

\begin{tabular}{|c|c|c|c|}
\hline Strain designation & Source & Host & Country \\
\hline CCUG 18727 & Abscess & Bovine & Australia \\
\hline Y4927 & Granuloma & Bovine & Australia \\
\hline CCUG 18728 & Lymph node & Bovine & Australia \\
\hline Z4479-1 & Lymph node & Bovine & Australia \\
\hline $93303-45$ & Joint & Bovine & Belgium \\
\hline B96/11 & unknown & Bovine & Belgium \\
\hline C1005 & Granuloma & Bovine & Denmark \\
\hline C1017 & Granuloma & Bovine & Denmark \\
\hline C1020 & Granuloma & Bovine & Denmark \\
\hline C1021-1 & Granuloma & Bovine & Denmark \\
\hline C1021-2 & Granuloma & Bovine & Denmark \\
\hline C1024 & Granuloma & Bovine & Denmark \\
\hline C1033 & Granuloma & Bovine & Denmark \\
\hline C1080-2 & Granuloma & Bovine & Denmark \\
\hline C1129-1 & Granuloma & Bovine & Denmark \\
\hline C1129-2 & Granuloma & Bovine & Denmark \\
\hline C1130-1 & Granuloma & Bovine & Denmark \\
\hline C1215-1 & Granuloma & Bovine & Denmark \\
\hline C1231-1 & Granuloma & Bovine & Denmark \\
\hline C1245-2 & Granuloma & Bovine & Denmark \\
\hline C1245-3 & Granuloma & Bovine & Denmark \\
\hline C1508-1 & Granuloma & Bovine & Denmark \\
\hline C1687 & Granuloma & Bovine & Denmark \\
\hline C772 & Granuloma & Bovine & Denmark \\
\hline C823 & Granuloma & Bovine & Denmark \\
\hline C867 & Granuloma & Bovine & Denmark \\
\hline C872 & Granuloma & Bovine & Denmark \\
\hline CCUG 27361 & Leg abscess & Bovine & Sweden \\
\hline CCUG 27360 & Lung & Bovine & Sweden \\
\hline $541 / 73$ & Granuloma & Bovine & UK \\
\hline CCUG 22228 & Lymph node & Bovine & UK \\
\hline NCTC 4985 & unknown & Bovine & UK \\
\hline CCUG 23133 & unknown & Bovine & unknown \\
\hline NCTC 4191 & Glands & Bovine & USA \\
\hline ATCC 49236 & unknown & Bovine & USA \\
\hline AC3 & Granuloma & Bovine & Zimbabwe \\
\hline $\mathrm{AC} 4$ & unknown & Bovine & Zimbabwe \\
\hline F126 & Oral cavity & Equine & Denmark \\
\hline F127 & Oral cavity & Equine & Denmark \\
\hline
\end{tabular}

Table 1 Actinobacillus lignieresii strains analysed (Continued)

\begin{tabular}{llll}
\hline F128 & Oral cavity & Equine & Denmark \\
F258 & Oral cavity & Equine & Denmark \\
F264 & Oral cavity & Equine & Denmark \\
C5309-b & Stomatitis & Equine & Denmark \\
F429 & Stomatitis & Equine & Denmark \\
T354/87 & Wound ${ }^{*}$ & Human & Australia \\
P1293 & Wound ${ }^{*}$ & Human & Denmark \\
F414 & Wound ${ }^{*}$ & Human & Norway \\
CCUG 38958 & Abscess & Ovine & Sweden \\
A7 & Abscess & Ovine & UK \\
A3 & Lung & Ovine & UK \\
A6 & Lymph node & Ovine & UK \\
HPA 107 & Rumen & Ovine & UK \\
HPA 119 & Rumen & Ovine & UK \\
Smith 40 & unknown & unknown & Australia \\
\hline
\end{tabular}

* due to horse bite.

Bacterial genomic DNA was extracted by using Easy$\mathrm{DNA}^{\circledR}$ kit (Invitrogen A/S, Taastrup, Denmark) according to the manufacturer's instruction. AFLP reaction was performed by using EcoRI and BspDI restriction enzymes as described previously [7]. Amplification products were detected on an ABI377 automated sequencer (Applied Biosystems, Naerum, Denmark) according to the manufacturer's instructions. Data collection and preprocessing were done by using GeneScan 3.1 software (Applied Biosystems). Numerical analysis was performed using BioNumerics software (Applied Maths, SintMartens-Latem, Belgium). In order to assess the reproducibility of the AFLP profiles, DNA specimens of seven strains were analysed in triplicates. Reproducibility was determined by direct comparison of densiometric curves by using Pearson product-moment correlation coefficient. Levels of similarity between normalized fingerprints were calculated by using binary Dice similarity coefficient $\left(S_{\mathrm{D}}\right)$. Clustering of fingerprints was performed with the unweighted pair group method using arithmetic averages (UPGMA). Significance of the clusters was determined by bootstrap analysis with 1000 samplings. The discriminatory power of AFLP was calculated by using Simpson's index of diversity [13].

Banding patterns obtained by amplification of EcoRI$B s p$ DI DNA templates with AFLP primers consisted of approximately 60 and 90 fragments in the size range 50-500 bp for equine/human and bovine/ovine isolates, respectively. The repeated analysis of identical samples showed highly reproducible result, although some variance in fluorescence intensity of AFLP fragments having identical size was observed. The variability observed was not sufficient to alter conclusions concerning relationship of one strain to another. Numerical comparison 


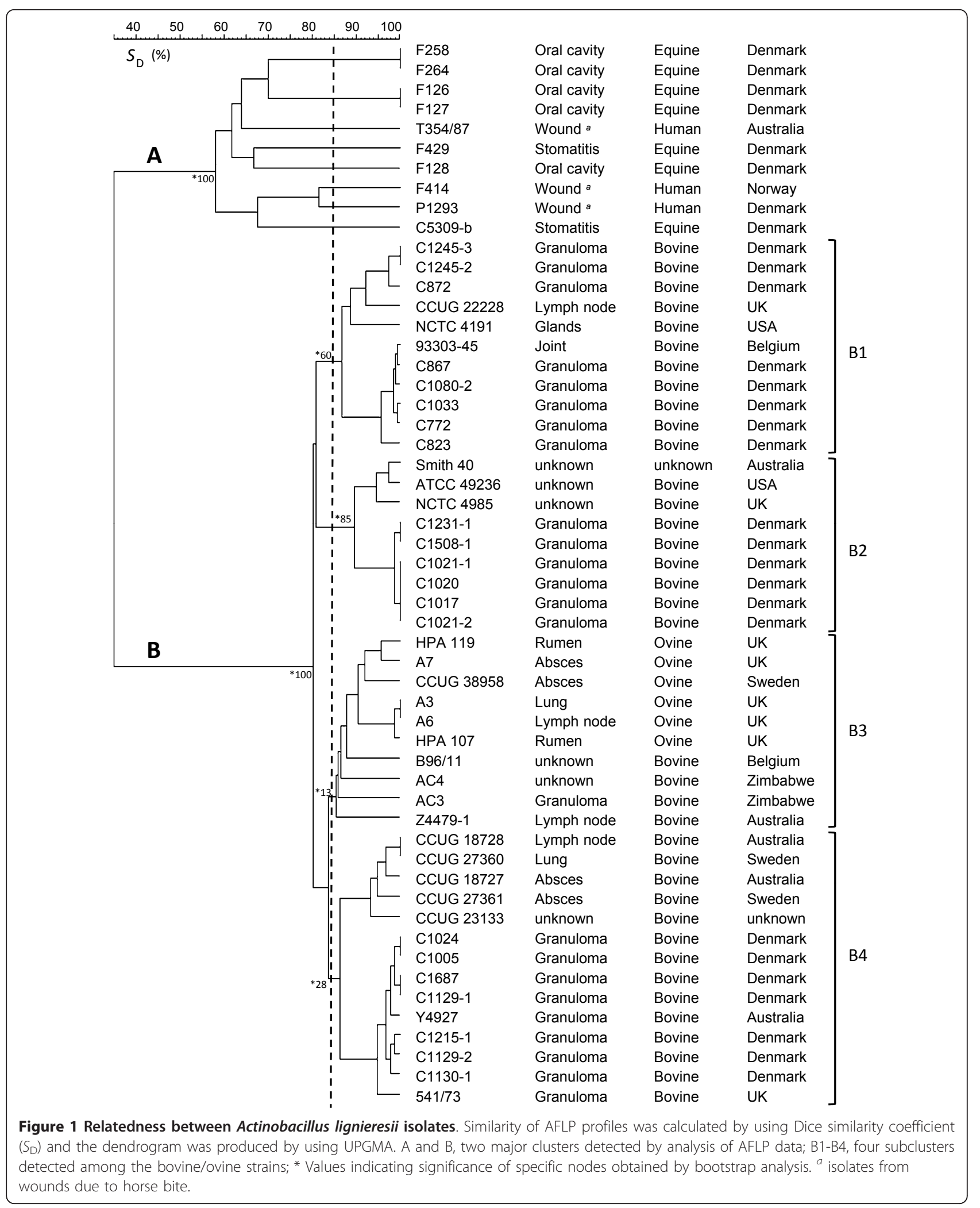


of AFLP densiometric curves of seven identical samples tested in triplicates showed an overall similarity level of $97.6 \pm 1.8 \%$.

In the present study 54 strains of $A$. lignieresii of animal and human origin were examined for genomic variation by using AFLP analysis. Among the strains tested 43 unique AFLP profiles were detected. Discriminatory index of the AFLP assay was 0.99.

Numerical analysis of AFLP data revealed two clearly distinguishable clusters; one consisting solely of strains isolated from horses and humans (cluster A; Figure 1), the other comprising strains of bovine and ovine origin (cluster B, Figure 1). Overall similarity between these two clusters was only $35 \%$.

The 10 analysed equine/human isolates showed eight distinct AFLP patterns forming a cluster at the linkage level of $58 \%$ (Figure 1; cluster A). With the exception of the strains F258 and F264 which had identical AFLP profiles, as well as strain F126, which had an AFLP profile identical to F127, all other strains within the group showed widely different genomic fingerprints (data not shown). That is particularly interesting in the light of the fact that the majority of equine/human strains tested derived from a relatively small geographic area, i.e. Denmark. The substantial chromosomal variability detected may indicate that changes in the genetic makeup within the group occur at a relatively high frequency. Isolates from horses and infected wounds of humans bitten by horses have previously been examined for their phenotypic characteristic, sequence variation in 16S rRNA genes and DNA-DNA hybridization by Christensen et al. [14]. Results obtained showed that these isolates represent a unique group of organisms, which is genetically, but not phenotypically, distinct from the type strain of A. lignieresii. Whole genome fingerprinting by AFLP analysis conducted in the present study provide further evidence to support the inclusion of these isolates in a distinct genomospecies of Actinobacillus as proposed by Christensen et al. [14].

The 44 analysed strains of bovine/ovine origin showed 35 distinct AFLP profiles forming a cluster at the linkage level of $80 \%$ (Figure 1; cluster B). Within the cluster, four subgroups could be recognised at the arbitrarily chosen cut-off value of $85 \%$ similarity (Figure 1; B1-B4). All of the subgroups detected within the bovine/ovine cluster consisted of strains derived from different geographic regions. Interestingly, within the cluster, many strains showed highly similar AFLP profiles in spite of widely different time and locality of isolation. For example, AFLP profile of strain 93303-45, which was isolated from a bovine joint in Belgium, differed by a single fragment from the profile obtained from strain C867 which was isolated from a bovine granuloma in Denmark. Moreover, strain CCUG 18728, which was isolated from a bovine lymph node in 1985 in Australia, showed an AFLP fingerprint identical to that obtained from strain CCUG 27360, which was isolated from a bovine lung in 1990 in Sweden. Under the assumption that identical AFLP profiles among different bacterial strains signify a direct descent from a common progenitor, results obtained in the present study indicate the existence of stable clonal lines in the natural population of A. lignieresii from bovine/ovine hosts.

One of the objectives of the present study was to investigate whether bovine and ovine isolates represent host specific genetic lineages of $A$. lignieresii. As revealed by numerical analysis of AFLP data, all ovine strains were included in a single subgroup (Figure 1; subgroup B3), showing relatively high (90\%) overall similarity of their AFLP profiles. However, the subgroup B3 included also bovine strains from Australia, Belgium and Zimbabwe, making it difficult to draw a firm conclusion concerning the existence of clonal lines specific for ovine hosts. In that connection it is worth noting that, according to the bootstrap values, the subgroup B3 appears to be the least stable of all recognized subgroups in the bovine/ovine clusters, and is therefore likely to be re-shuffled by inclusion of additional strains.

In conclusion, analysis of EcoRI-BspDI AFLP markers has been shown to represent a sensitive and reliable approach for differentiation of $A$. lignieresii, which render it useful for both classification and epidemiological tracing of individual clones. The results of the present study revealed a substantial degree of genetic diversity among the strains isolated from horses and infected wounds of humans bitten by horses, while a comparatively lower degree of genetic diversity was observed for strains of bovine/ovine hosts. Some clonal lines among bovine/ovine strains appear to be genetically stable over the time and can be found in very distant geographic locations. However, the existence of clonal lines that are adapted specifically to ovine hosts is not obvious and further studies are needed for full clarification.

\section{Acknowledgements}

Authors thank Mahshad Rezaali for technical assistance.

\section{Author details}

'Division of Veterinary Diagnostics and Research, National Veterinary Institute, Technical University of Denmark, Bülowsvej 27, DK-1790 Copenhagen V, Denmark. ${ }^{2}$ Department of Veterinary Disease Biology, Faculty of Life Sciences, University of Copenhagen, Stigbøjlen 4, DK-1870 Frederiksberg C, Denmark.

\section{Authors' contributions}

BK participated in the design of the study, carried out AFLP analysis and drafted the manuscript.

$\varnothing \mathrm{A}$ participated in the design of the study and carried out bacteriological examination of the isolates.

$M B$ participated in the design of the study, carried isolation and

bacteriological examination of the isolates and drafted the manuscript.

All authors read and approved the final manuscript. 


\section{Competing interests}

The authors declare that they have no competing interests.

Received: 15 December 2010 Accepted: 8 February 2011

Published: 8 February 2011

\section{References}

1. Bisgaard M: Ecology and significance of Pasteurellaceae in animals. Zentralbl Bacteriol 1993, 279:7-26.

2. Biberstein EL: Haemophilus-Pasteurella-Actinobacillus: their significance in veterinary medicine. In Haemophilus, Pasteurella and Actinibacillus. Edited by: Kilian M, Frederiksen W, Biberstein EL. London: Academic Press; 1981:61-73.

3. Chladek DW, Ruth GR: Isolation of Actinobacillus lignieresii from an epidural abscess in a horse with progressive paralysis. J Am Vet Med Assoc 1976, 168:64-66.

4. Zaharija I, Modric Z, Naglic T: Spontaneous infection with Actinobacillus lignieresii in horses: study of the first case in Croatia. Vet Arh 1979, 49:105-112.

5. Rycroft AN, Garside LH: Actinobacillus species and their role in animal disease. Vet J 2000, 159:18-36.

6. Fusing V, Paster BJ, Dewhirst FE, Poulsen LK: Differentiation of Actinobacillus pleuropneumoniae strains by sequence analysis of $16 \mathrm{~S}$ rDNA and ribosomal intergenic regions, and development of a species specific oligonucleotide for in situ detection. Syst Appl Microbiol 1998, 21:408-418.

7. Kokotovic B, Angen Ø: Genetic diversity of Actinobacillus pleuropneumoniae assessed by amplified fragment length polymorphism analysis. J Clin Microbiol 2007, 45:3921-3929.

8. Bojesen AM, Christensen H, Nielsen SS, Bisgaard M: Host-specific bacterial lineages in the taxon 2 and 3 complex of Pasteurellaceae. Syst App/ Microbiol 2007, 30:119-127.

9. Bojesen AM, Larsen J, Pedersen AG, Mörner T, Mattson R, Bisgaard M: Identification of a novel Mannheimia granulomatis lineage from lesions in roe deer (Capreolus capreolus). J Wildlife Dis 2007, 43:345-352.

10. Bojesen AM, Bisgaard M, Christensen H: Identification of host-specific subclones within Mannheimia varigena. Pasteurellaceae 2005. ASM Conference in collaboration with the International Pasteurellaceae Society: 2326 October 2005; Hawaii; American Society for Microbiology; 2005, 44.

11. Blackall PJ, Bojesen AM, Christensen H, Bisgaard M: Reclasification of [Pasteurella] trehalosi as Bibersteinia trehalosi gen. nov., comb. nov. Int $]$ Syst Evol Microbiol 2007, 57:666-674.

12. Bojesen AM, Torpdahl M, Christensen H, Olsen JE, Bisgaard M: Genetic diversity of Gallibacterium anatis isolates from different chicken flocks. J Clin Microbiol 2003, 41:2737-2740.

13. Hunter PR, Gaston MA: Numerical index of the discriminatory ability of typing systems: an application of Simpson's index of diversity. J Clin Microbiol 1988, 26:2465-2466.

14. Christensen $H$, Bisgaard M, Angen $\varnothing$, Olsen JE: Final classification of Bisgaard taxon 9 as Actinobacillus arthritidis sp. nov. and recognition of a novel genomospecies for equine strains of Actinobacillus lignieresii. Int J Syst Evol Microbiol 2002, 52:1239-1246.

doi:10.1186/1751-0147-53-6

Cite this article as: Kokotovic et al: Genetic diversity of Actinobacillus lignieresii isolates from different hosts. Acta Veterinaria Scandinavica 2011 53:6.

\section{Submit your next manuscript to BioMed Central and take full advantage of:}

- Convenient online submission

- Thorough peer review

- No space constraints or color figure charges

- Immediate publication on acceptance

- Inclusion in PubMed, CAS, Scopus and Google Scholar

- Research which is freely available for redistribution 